\title{
O ENSINO DO VERBO: TEMPO E ASPECTO COMO CATEGORIAS SEMÂNTICO-DISCURSIVAS
}

\author{
Maria Valíria Aderson de Mello Vargas*
}

\section{Introdução}

Como ponto de partida para a discussão, consideremos as seguintes ideias: o fenômeno do aspecto verbal é estreitamente vinculado à categoria do tempo; o tempo associa o evento ao momento em que é enunciado e a um momento de referência; o aspecto exprime o tempo que é inerente ao evento, ou seja, o tempo de desenvolvimento desse evento. Ambas as categorias, portanto, apoiam-se na noção de tempo.

Estudiosos costumam contrapor as noções semânticas que envolvem o tempo (noções de presente, de passado e de futuro) às noções relacionadas ao aspecto: noções de duração, instantaneidade, começo, desenvolvimento e fim, ou seja, noções que dizem respeito à maneira como é tratado o tempo decorrido dentro dos limites do fato narrado.

Tomemos um exemplo. Numa frase como Estudávamos filosofia no colégio, a forma verbal "estudávamos" tanto pode indicar tempo passado quanto pode referir-se ao desenvolvimento/duração da ação de estudar, ou seja, pode manifestar o aspecto durativo.

Considerem-se os seguintes enunciados, distribuídos num eixo imaginário, numa "linha do tempo", em que se marcam os três momentos temporais:

PASSADO

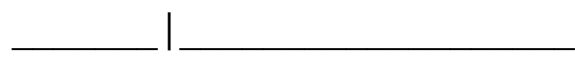

Estudei filosofia naquele ano.
PRESENTE |||||| $\mid$

Estudo filosofia hoje.
FUTURO

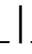

Estudarei filosofia no ano que vem.

\footnotetext{
* Professora doutora aposentada do Departamento de Letras Clássicas e Vernáculas da Faculdade de Filosofia, Letras e Ciências Humanas da Universidade de São Paulo (FFLCH-USP) e membro do corpo permanente do Programa de Mestrado em Linguística da Universidade Cruzeiro do Sul.
} 
Acerca do enunciado Estudo filosofia hoje é possível afirmar: a) expressa um fato que se desenvolve no momento em que idealmente se situa o falante; b) o processo é contemporâneo ao momento da enunciação e c) nota-se um valor genérico e habitual do evento expresso pela forma verbal de presente.

A respeito da ação de estudar, em Estudei filosofia naquele ano, pode-se dizer que se desloca para antes do momento em que o falante está situado temporalmente, portanto que ocorreu no passado; o evento reduz-se a uma espécie de ponto indivisível.

Já em estudarei filosofia no ano que vem, infere-se que a ação expressa um fato que ocorrerá no futuro; o foco da ação situa-se posteriormente ao ponto em que se situa o falante.

Portanto, o tempo de referência dos três enunciados é o presente (o momento da fala, aqui e agora) e esse tempo organiza o passado e o futuro de acordo com o momento da enunciação, de acordo, portanto, com o papel do falante como enunciador que relaciona tudo ao seu ponto de vista.

Direcionamos, assim, a discussão para a análise dos dois aspectos considerados básicos pelos gramáticos e estudiosos em geral do fenômeno do verbo: a) o perfectivo, que é definido como a expressão de um fato tomado em seu completamento, ou seja, um fato concluído, acabado, e b) o imperfectivo, que compreende as várias fases de um processo considerado em seu desenvolvimento, em sua duração e continuidade.

Partimos do princípio de que o tempo e o aspecto são categorias, sobretudo, semântico-discursivas, que marcam efetivamente os enunciados. Buscamos, assim, apontar algumas marcas temporais e aspectuais que se revelam nas diferentes formas de exprimir os sentidos dos verbos.

Depois de apresentar algumas considerações sobre o ensino da gramática, conforme preveem os Parâmetros Curriculares Nacionais, sugerimos algumas atividades que envolvem a aplicação de novas ideias ao ensino do português. Buscamos demonstrar que o estudo da expressão verbal pode transformar-se num efetivo exercício de identificação dos rastros que o sujeito enunciador deixa de si mesmo no discurso, daquilo que pretende dizer, de suas opiniões e crenças, do que pretende compartilhar com seu interlocutor.

Temos em vista, afinal, que o objetivo básico desse ensino é levar o aluno a utilizar adequadamente os mecanismos linguísticos nas mais variadas situações de interação social, de leitura e de produção de textos.

A questão que permeia a discussão é: de que maneira podemos levar o aluno a reconhecer as categorias de tempo e de aspecto como fenômenos semânticos, ou seja, como fatores essenciais na construção de sentido dos textos?

\section{O ensino de gramática: as propostas dos PCNs}


Nos Parâmetros Curriculares Nacionais, enfatiza-se a necessidade de dar ao aluno condições de ampliar o domínio da língua e da linguagem, de desenvolver seus conhecimentos discursivos e linguísticos e de prepará-lo, dessa forma, para o exercício da cidadania. Lê-se, num dos trechos desse documento:

Uma vez que as práticas da linguagem são uma totalidade e que o sujeito expande sua capacidade de uso da linguagem e de reflexão sobre ela em situações significativas de interlocução, as propostas didáticas de ensino de Lingua Portuguesa devem organizar-se tomando o texto (oral ou escrito) como unidade básica de trabalho, considerando a diversidade de textos que circulam socialmente. Propõe-se que as atividades planejadas sejam organizadas de maneira a tornar possivel a análise crítica dos discursos para que o aluno possa identificar pontos de vista, valores e eventuais preconceitos neles veiculados. Assim organizado, o ensino de Língua Portuguesa pode constituir-se em fonte efetiva de autonomia para o sujeito, condição para a participação social responsável.

(Fonte: PCNs, 1998: 58-59.)

Infere-se do trecho citado que o ensino gramatical não deve ser realizado desvinculadamente das práticas de linguagem, ou seja, de forma descontextualizada, por meio da simples exposição de quadros sinóticos das formas verbais ou de um conjunto de regras de concordância, regência, colocação pronominal, reforçadas por exercícios de identificação e classificação. Na seleção dos conteúdos de análise linguística, conforme lemos nos PCNs, não devem predominar as imposições de organização clássica da gramática escolar. O que vai ser ensinado deve estar de acordo com as necessidades apresentadas pelos alunos nas atividades de produção, leitura e escuta de textos.

A ideia que predomina, assim, é a de que o ensino da gramática deve ser contextualizado e centrado no texto. Resta saber, entretanto, se essa orientação alcança, de fato, o universo escolar. O professor toma conhecimento desses modelos, discute-os com seus pares, aplica-os em suas atividades didáticas?

Nossa preocupação se justifica, entre outros motivos, por constatarmos, nos Parâmetros Curriculares Nacionais - Ensino Médio, publicados dois anos depois dos PCNs do Ensino Fundamental, portanto em 2002, evidências de que as falhas se perpetuam no ensino da gramática.

Eis o que lemos nos seguintes trechos do novo documento:

A perspectiva dos estudos gramaticais na escola até hoje centra-se, em grande parte, no entendimento da nomenclatura gramatical como eixo principal: descrição e norma se confundem na análise da frase, esta deslocada do uso, da função e do texto.

O estudo gramatical aparece nos planos curriculares de Português, desde as séries iniciais, sem que os alunos, até as séries finais do Ensino Médio, dominem a 
nomenclatura. Estaria a falha nos alunos? Será que a gramática que se ensina faz sentido para aqueles que sabem gramática porque são falantes nativos? A confusão entre norma e gramaticalidade é o grande problema da gramática ensinada pela escola. $O$ que deveria ser um exercício para o falar/escrever/ler melhor se transforma em uma camisa de força incompreensivel.

(Fonte: PCNs - Ensino Médio, 2002, p. 137.)

Sabemos que é ainda comum a preocupação de muitos professores em reconstruir com os alunos o quadro descritivo constante dos manuais de gramática escolar, ou seja, em construir paradigmas morfológicos, em discutir os pontos de gramática, as classes de palavras com suas múltiplas subdivisões, as regras de concordância, com suas exceções reconhecidas.

Nas gramáticas e nos materiais didáticos (livros, apostilas, manuais de orientação ao professor etc.), o tratamento dado ao verbo, em geral, limita-se à exposição de modelos de conjugação, com todas as formas temporais e modais, sem que se explique, por exemplo, por que alguns verbos permitem certas construções e outros não. Também não se esclarecem as razões do uso de locuções e perífrases verbais, em vez da adoção das formas simples. Tais modelos não dão conta, portanto, de toda a significação possível do verbo.

Infelizmente, não se discute o essencial, isto é, as marcas que o sujeito enunciador deixa de si mesmo ao utilizar as formas verbais para expressar-se, oralmente ou por escrito, e, ainda, o que pretende dizer ao ouvinte/leitor e como quer que este interprete o que foi dito.

\section{As categorias semântico-discursivas de tempo e de aspecto no ensino do verbo}

Diante da situação acima descrita, é, sem dúvida, necessário buscar caminhos para transformar o ensino dos fenômenos gramaticais em efetivas reflexões linguísticas. No ensino do verbo, por exemplo, isso significa tratar essa categoria gramatical como um dos mecanismos essenciais da língua, que permite ao sujeito/falante/usuário expressar certezas, desejos, comandos, emoções e, sobretudo, buscar a cumplicidade do interlocutor na expressão de tudo o que pretende comunicar.

O pressuposto básico é que o estudo das categorias de tempo e de aspecto, consideradas em sua dimensão semântico-discursiva, pode contribuir para que o aluno desenvolva a competência linguística e saiba compreender e utilizar os mecanismos disponíveis na língua para criar sentido.

Como exemplo para a análise dessas categorias, tomemos um pequeno trecho de um romance de Jorge Amado e observemos as formas verbais (grifos nossos). 


\begin{abstract}
O Trapiche
Sob a lua, num velho trapiche abandonado, as crianças dormem.

Antigamente aqui era o mar. Nas grandes e negras pedras dos alicerces do trapiche as ondas ora se rebentavam fragorosas, ora vinham se bater mansamente. A água passava por baixo da ponte sob a qual muitas crianças repousam agora, iluminadas por uma réstia amarela de lua. Desta ponte saíram inúmeros veleiros carregados, alguns eram enormes e pintados de estranhas cores, para a aventura das travessias marítimas. Aqui vinham encher os porões $e$ atracavam nesta ponte de tábuas, hoje comidas. Antigamente diante do trapiche se estendia o mistério do mar oceano, as noites diante dele eram de um verde escuro, quase negras, daquela cor misteriosa que é a cor do mar à noite.

Hoje a noite é alva em frente ao trapiche. É que na sua frente se estende agora o areal do cais do porto. Por baixo da ponte não há mais rumor de ondas. A areia invadiu tudo, fez o mar recuar de muitos metros. Aos poucos, lentamente, a areia foi conquistando a frente do trapiche. Não mais atracaram na sua ponte os veleiros que iam partir carregados. Não mais trabalharam ali os negros musculosos que vieram da escravatura. Não mais cantou na velha ponte uma canção um marinheiro nostálgico.

(AMADO, Jorge. Capitães da Areia. S.Paulo: Companhia das Letras, 2008, p. 27.)
\end{abstract}

Um ponto de partida para a análise das formas verbais desse trecho é levar o aluno a perceber que se instaura no texto um sujeito/locutor que assume o papel de narrador de fatos ocorridos num mundo ficcional, num passado distante do mundo real e que, para isso, faz uso das formas verbais, instigando seu interlocutor a participar da construção de sentido do texto.

É interessante lembrarmos, nesse ponto, a distinção que Weinrich (1974) estabelece entre o mundo comentado e o mundo narrado, tendo em vista as diferentes situações comunicativas expressas pelas formas verbais. Ao mundo comentado, pertencem a lírica, o drama, o ensaio, o diálogo, o comentário, enfim, as situações comunicativas que não consistem em relatos; ao mundo narrado, pertencem todos os tipos de relato, literários ou não, em que a situação comunicativa se desloca para outro plano, o plano de consciência, situado além da temporalidade do mundo comentado, que deixa de ter validade enquanto durar o relato.

Voltando ao texto de Jorge Amado, nada obriga o locutor a relacionar o relato com o tempo passado, uma vez que o mundo narrado, diferentemente do mundo comentado, é indiferente ao tempo cronológico. Essa ideia se comprova com as construções de presente empregadas no trecho citado de Jorge Amado e que deveriam ser apresentados por meio de formas verbais do passado, indicando ações concluídas (aspecto perfectivo), porém não o são:

Sob a lua, num velho trapiche abandonado, as crianças dormem. 
Hoje a noite é alva em frente ao trapiche. É que na sua frente se estende agora o areal do cais do porto. Por baixo da ponte não há mais rumor de ondas.

... daquela cor misteriosa que é a cor do mar à noite.

Revela-se, assim, o interesse, da parte do locutor/enunciador, em referir-se ao processo que conduz ao evento em questão; parece interessar a ele apresentar as ações em seu desenvolvimento, como se sua duração fosse ampliada num efeito de câmera lenta.

Assim, serão as mais adequadas, nesse caso, as questões de interpretação que busquem conduzir o aluno a refletir sobre essa intencionalidade do sujeito que narra os fatos e a relacioná-la à escolha de certas formas verbais e não de outras. Por essa razão, cabem também as comparações dessas formas de presente com as de pretérito, utilizadas no texto. $\mathrm{O}$ aluno, certamente, perceberá os efeitos de sentido provocados pelo uso do pretérito perfeito (perfectivo, por natureza), que situa as ações num passado distante, já realizado, muitas vezes que se quer mesmo esquecer:

Desta ponte saíram inúmeros veleiros carregados...

A areia invadiu tudo, fez o mar recuar de muitos metros...

Não mais trabalharam ali os negros musculosos que vieram da escravatura.

Não mais cantou na velha ponte uma canção um marinheiro nostálgico.

Notará também que as formas de pretérito imperfeito (imperfectivas) transmitem a sensação de prolongamento das ações. Retomemos dois trechos em que essas formas ocorrem:

Antigamente aqui era o mar. Nas grandes e negras pedras dos alicerces do trapiche as ondas ora se rebentavam fragorosas, ora vinham se bater mansamente. A água passava por baixo da ponte...

Aqui vinham encher os porões e atracavam nesta ponte de tábuas, hoje comidas. Antigamente diante do trapiche se estendia o mistério do mar oceano, as noites diante dele eram de um verde escuro, quase negras...

O pretérito imperfeito é conhecido como passado narrativo. A própria denominação desse tempo denota seu valor intrínseco, que é o de apresentar um fato que se desenvolvia no passado, mas que não se sabe, nem interessa saber, quando ou se acaba. O efeito de sentido provocado por esse uso é o de que as ações se prolongam, não acabam, projetam-se para o presente. Quem narra procura, desse modo, apresentar os acontecimentos com minúcias, fazer ver os diversos momentos da ação e dos acontecimentos.

O aluno notará, também facilmente, que a intenção de prolongar a descrição do ambiente, no texto, reforça-se com a presença da locução verbal de gerúndio (imperfectivo, por natureza) no trecho:

Aos poucos, lentamente, a areia foi conquistando a frente do trapiche. 
A comparação entre as formas verbais pode levar esse aluno a pensar nas razões que levaram o sujeito/falante a utilizá-las e de perceber que os sentidos por elas expressos ultrapassam o âmbito do tempo, do modo, da pessoa, do número e da voz.

O texto, assim, transforma-se num efetivo objeto de ensino, em que o aluno é levado a compartilhar, de fato, a construção do sentido e, ao mesmo tempo, atribuir significado ao que aprende, por meio da exploração das possibilidades e dos recursos da linguagem. Torna-se, portanto, um instrumento eficiente para a compreensão de que podemos utilizar a língua de modo variado, por meio de estratégias de convencimento do interlocutor/leitor e com vistas a produzir diferentes efeitos de sentido.

É desse modo que se pode reconhecer o valor dos usos da linguagem, determinados historicamente, de acordo com as demandas sociais de cada situação.

Torna-se bem interessante, ainda, um trabalho de comparação entre os modos de utilizar as formas verbais em textos de diferentes gêneros. Pensemos nessa comparação, ao lermos um trecho da seguinte notícia:

\footnotetext{
Crescida, 1 "Tainá" quer distância da Amazônia

A indiazinha que não tinha energia elétrica em casa agora mora em São Paulo e quer ser estilista. Aos 19 anos, Eunice Baía, que interpretou Tainá nos dois primeiros filmes da série, vive adaptada à cidade grande. Nem pensa em voltar para a zona rural de Barcarena (PA), onde foi encontrada pela equipe do filme quando tinha sete anos, ainda na década de 1990.

"Aqui é um absurdo de diferente de lá. Eu me apaixonei por São Paulo", conta com sotaque paulistano a descendente de indios da etnia baré.

Eunice foi morar em São Paulo aos oito anos, após as filmagens de "Tainá - Uma Aventura na Amazônia”, lançado em 2001. Não sabia ler e escrever. Hoje falando com desenvoltura, diz que, até depois do segundo filme - "Tainá 2 - A Aventura Continua", de 2004 -, travava ao dar entrevista.

Ela foi adotada pela produtora de atriz Noêmia Duarte, que fez a seleção de elenco do filme. As duas, que se chamam de mãe e filha, vivem em Santa Cecília, centro de São Paulo. "Acho que é um carma, foi amor à primeira vista", afirma Noêmia.
}

(Rodrigo Vizeu. Folha de S.Paulo, 14/3/2010)

Torna-se evidente que o texto acima também se situa no plano do mundo narrado. Instaura-se na notícia um narrador observador dos fatos, situado no presente e que considera esses fatos a partir desse presente (o momento da fala).

Portanto, antes de nos preocuparmos com a classificação das formas verbais segundo os tempos e modos, que deve ser feita numa etapa posterior, devemos atentar para seu uso e para os efeitos de sentido que provocam nas mais diversas situações de interação.

Levar os alunos a formularem hipóteses sobre as intenções dos produtores desses textos e, também, sobre os efeitos de sentido provocados pelos usos das formas verbais predominantes é tarefa que pode surtir bons resultados. 
Retomemos o texto e comparemos as formas de presente com as de passado, expressas no seguinte trecho:

A indiazinha que não tinha energia elétrica em casa agora mora em São Paulo e quer ser estilista. Aos 19 anos, Eunice Baía, que interpretou Tainá nos dois primeiros filmes da série, vive adaptada à cidade grande.

Fica clara a oposição entre os aspectos perfectivo e imperfectivo, este revelado pelas formas de presente do indicativo, que denota os fatos atuais (ter energia elétrica, morar em São Paulo, querer ser estilista, viver adaptada), contemporâneos ao momento da fala. A ação se investe de um caráter durativo, próprio para marcar a permanência das ações no tempo.

Numa análise em que se levasse em conta o caráter aspectual das formas verbais, caberia perguntar, por exemplo, se o aluno notou as diferenças de sentido, que o próprio texto revela, no uso do perfeito (interpretou) e do presente dos verbos.

Tal questão poderia conduzi-lo a uma verdadeira reflexão linguística, tão cara ao desenvolvimento dos processos mentais do sujeito. Haveria a aposta na capacidade de o aluno formular explicações para um fenômeno gramatical que envolve a intenção do enunciador de localizar num passado remoto a ação de interpretar a personagem no filme.

Manifestam-se, ainda, no texto em questão, outras marcas aspectuais interessantes. Uma delas é o uso da forma nominal de particípio, no título da notícia (Crescida, $1^{a}$ "Tainá" quer distância da Amazônia), para caracterizar o estado atual da jovem atriz. Essa forma de particípio substituiu a forma de pretérito perfeito "cresceu", que exprimiria simplesmente o passado. É possível levantar uma série de hipóteses para justificar essa substituição. Uma delas é pressupor que o sentido expresso pelo particípio passado do verbo crescer sugere, mais concretamente e mais objetivamente, o estado da atriz. Percebemos que interessa mais caracterizá-la, descrevê-la pelo efeito de sentido do verbo crescer, do que transformá-la no sujeito agente desse verbo.

Comparemos as duas situações, expostas no seguinte quadro:

\begin{tabular}{|l|l|}
\hline Texto original & Texto transformado \\
\hline Crescida, 1a "Tainá" quer distância da Amazônia & $\begin{array}{l}\text { A 1 } 1^{a} \text { "Tainá”, que cresceu, quer distância da } \\
\text { Amazônia. }\end{array}$ \\
\hline
\end{tabular}

Assim, notamos que, se o verbo fosse expresso no pretérito perfeito ("cresceu"), o fato estaria situado num passado abstrato, longínquo, concluído. A forma de particípio (crescida), mesmo desacompanhada de auxiliar, "espacializa-se", aspectualiza-se, para expressar um fato passado ou um estado mais ou menos definitivo, "cravado" no tempo. 
Interessante é também notar que o particípio passado se caracteriza como uma forma morfologicamente nominal, mas assume uma função sintaticamente verbal.

Os particípios são, na verdade, adjetivos que podem conter as marcas nominais de feminino e de número plural em /s/. Temos, no mesmo texto, outro exemplo: ...vive adaptada à cidade grande... São nomes-adjetivos, que, em vez de expressar a qualidade de um ser, expressam, semanticamente, processos que nele se passam. Pertencem, sob o ponto de vista da morfologia, à classe dos adjetivos, porém, no âmbito semântico e sintático, seu valor é verbal.

É interessante notar que, por essa razão, as formas nominais de particípio passado são consideradas como verdadeiros adjetivos: por assumirem a função determinante do adjetivo, ampliam o sentido dos substantivos a que se referem. É uma ótima chance de levar o aluno a compreender por que essas formas são classificadas como "formas nominais" do verbo.

Vale, ainda, comparar o uso dessa forma de particípio com as de outros particípios que ocorrem no texto:

...onde foi encontrada pela equipe do filme...

Ela foi adotada pela produtora de atriz Noêmia Duarte...

Diferentemente do particípio utilizado no título da notícia, as formas de particípio grifadas acima compõem duas construções da voz passiva (foi encontrada e foi adotada). Tais formas são marcadas muito mais pelo tempo (que caracteriza o verbo auxiliar ser, no perfeito), do que pelo aspecto.

Cabe, também, observar o efeito de prolongamento, de "espacialização" da fala da atriz, provocado pelo uso da forma de gerúndio (aspectual, por natureza), no trecho:

Hoje falando com desenvoltura, diz que (...) travava ao dar entrevista.

Esse efeito de sentido de espacialização da ação fica mais claro se compararmos as duas situações de uso, conforme se apresentam no quadro abaixo.

\begin{tabular}{|l|l|}
\hline Situação 1 (Texto original) & Situação 2 (Trecho recriado) \\
\hline $\begin{array}{l}\text { Hoje falando com desenvoltura, diz que (...) } \\
\text { travava ao dar entrevista. }\end{array}$ & $\begin{array}{l}\text { Hoje fala com desenvoltura e diz que (...) travava } \\
\text { ao dar entrevista. }\end{array}$ \\
\hline
\end{tabular}


Notamos que, no caso de uso da forma de presente ("fala"), no trecho transformado, não se cria o efeito de instantaneidade da ação de "falar", expresso pela forma de gerúndio do texto original. O mais interessante, entretanto, é perceber que esse efeito de contemporaneidade, de ação em desenvolvimento, contribui, em grande medida, para sugerir, no texto original, o próprio desenrolar da fala da atriz.

Ao comparar a construção de gerúndio com a de presente, o próprio aluno estará fazendo inferências, construindo sentidos, manipulando recursos que a língua coloca à disposição do usuário. Estará buscando, sobretudo, compreender as opções dos falantes/usuários da língua por determinadas formas e não por outras.

Em atividades como as sugeridas acima, enfim, as formas verbais passam a ser tratadas como verdadeiras práticas discursivas. Os sujeitos que as utilizam sempre têm uma razão para suas escolhas, sempre relacionadas à intenção de comunicar algo a alguém, em determinado tempo e espaço. Para o alcance de seu objetivo, selecionam sempre um modo de dizer adequado a seu intento.

\section{Considerações finais}

Buscamos aqui demonstrar que as categorias de tempo e de aspecto devem ser examinadas, sobretudo, como categorias semânticas e discursivas, ou seja, como verdadeiros processos enunciativos de construção de sentido. Entendemos que é fundamental observar o verbo como um fenômeno linguístico passível de promover a interpretação, o debate, a pesquisa e a troca de experiências.

Insistimos em que se deve promover, no ensino, uma prática voltada para a reflexão produzida pelos próprios alunos, diante dos textos de variados gêneros e mediante a utilização de uma terminologia simples e que se aproxime, progressivamente, pela mediação do professor, do conhecimento gramatical produzido.

Essa prática é muito diferente da metodologia clássica, centrada na definição, classificação e exercitação dos fenômenos linguísticos, em que não se oferece ao aluno a oportunidade de alcançar resultados diferentes daqueles obtidos pela gramática tradicional, cuja descrição, em muitos aspectos, não corresponde aos usos reais da linguagem.

O que se quer ressaltar é que podemos desenvolver um trabalho efetivo de reflexão gramatical, integrado à leitura, que considere o texto como uma real unidade de sentido e promova a participação efetiva dos alunos nessa reflexão.

Apropriando-se adequadamente do conteúdo selecionado, por exemplo, dos usos das formas verbais, e tendo a oportunidade de desenvolver as habilidades pretendidas, os alunos, certamente, aprenderão com o texto e encontrarão razões que motivem o aprendizado desse conteúdo. 
A leitura e a interpretação do texto, afinal, devem ser consideradas como atividades necessárias aos estudos gramaticais, de acordo com o que se lê nos PCNs:

Os princípios organizadores dos conteúdos de Língua Portuguesa USO => REFLEXÃO => USO, além de orientarem a seleção dos aspectos a serem abordados, definem, também, a linha geral de tratamento que tais conteúdos receberão, pois caracterizam um movimento metodológico de $A C ̧ \tilde{A} O=>$ REFLEX $\tilde{A} O=>A C ̧ \tilde{A} O$ que incorpora a reflexão às atividades linguísticas do aluno, de tal forma que ele venha a ampliar sua competência discursiva para as práticas de escuta, leitura e produção de textos.

Fonte: Parâmetros Curriculares Nacionais, 1998: 59-60.

O que se prevê, desse modo, é que o estudo da gramática leve o aluno a tornar-se leitor e produtor eficiente de textos orais e escritos que circulam socialmente. Para isso, é preciso que ele se acostume a estabelecer relações de sentido, compreendendo, de fato, o significado e a verdadeira função da palavra no contexto em que ela aparece.

Adotando-se essa perspectiva, o estudo da língua passa a ser desenvolvido em seus aspectos morfológicos, sintáticos e semântico-pragmáticos. O aluno adquire, assim, a prática de identificar as regularidades linguísticas e de analisá-las, aplicando os conhecimentos, durante as atividades de leitura e de produção de textos, num processo de ação/reflexão/ação.

\section{Referências Bibliográficas}

BRASIL. Secretaria de Educação Fundamental. Parâmetros Curriculares Nacionais. Introdução. Ensino Fundamental $3^{\circ}$ e $4^{\circ}$ ciclos. Brasília: MEC/ Secretaria de Educação Fundamental , 1998.

BRASIL. Secretaria de Educação Fundamental. Parâmetros Curriculares Nacionais de Língua Portuguesa. $3^{\circ}$ e $4^{\circ}$ ciclos. Brasília: MEC/ Secretaria de Educação Fundamental , 1998a.

BRASIL. Secretaria de Educação Média e Tecnológica. Parâmetros Curriculares Nacionais: ensino médio. Brasília: MEC/ SEMTEC, 2002.

WEINRICH, H. Estructura y función de los tiempos en el lenguaje. Trad. Federico Latorre. Madrid: Gredos, 1974. 